\title{
Protective Effect of Encapsulated Nanocurcumin- PEGOA against Oxidative Damage on Human Mesenchymal Stem Cells Exposed to Hydroquinone as a Risk Factor for Leukemia
}

\author{
Shima Nazem ${ }^{1}$, Mahbobeh Masoumi ${ }^{1}$, Naser Amirizadeh ${ }^{2}$, Fatemeh \\ Zolghadr ${ }^{1}$, Majid Sadeghizadeh ${ }^{1,}$ \\ ${ }^{1}$ Department of Genetics, Faculty of Biological Sciences, Tarbiat Modares University, \\ Tehran, Iran \\ ${ }^{2}$ Research Center of High Institute for Research and Education in Transfusion Medicine, \\ Tehran, Iran \\ * Corresponding author: Majid Sadeghizadeh, Department of Molecular Genetics, \\ Faculty of Biological Sciences, Tarbiat Modares University, P.O. Box 14115-154, \\ Tehran,Iran.E-mail: sadeghma@modares.ac.ir
}

DOI: $10.21859 / \mathrm{mci}-01011$

Submitted: 14 March 2016

Revised: 20 July 2016

Accepted: 3 August 2016

ePublished: 08 September 2016

Keywords:

Nanocapsules

Hydroquinone

Mesenchymal Stromal Cells

Oxidative Stress

qRT-PCR

\begin{abstract}
Introduction: Benzene a well-known environmental pollutant is a human carcinogen which is involved in the manifestation of a number of malignancies. Activation of benzene and its reactive metabolites such as hydroquinone (HQ) leads to continuous production of reactive oxygen species (ROS), causing oxidative Stress.

Curcumin, the yellow pigment of curcuma longa, has been shown to possess antioxidant activity in vitro and in vivo. However, poor bioavailability is the major drawback about of this drug. By using dendrosome, a nontoxic nanoparticle, we tried to deal with this problem. In the present study, we have investigated the protective effects of encapsulated nanocurcumin-PEGOA (ENC) against the HQ-induced oxidative damage in human mesenchymal bone marrow stem cells (hMSCs).

Methods: hMSCs were pre-treated with ENC and then exposed to HQ. Cell viability, intracellular ROS and lipid peroxidation extent were assessed by MTT assay, DCFHDA fluorescent dye and thiobarbituric acid reactive substances (TBARS), respectively. Moreover, mRNA levels of antioxidant enzymes, catalase and hemeoxygenase- 1 were evaluated by qRT-PCR.

Results: The results showed that treatment of MSCs with ENC $(10 \mu \mathrm{M})$ for 12 hours prior to HQ exposure, significantly attenuated the cell viability loss, suppressed the elevation of ROS and reduced the extent of lipid peroxidation caused by HQ compared with the control. Moreover, a significant increase in mRNA expression of antioxidant genes of catalase and hemeoxygenase-1 was observed after treatment with ENC.

Conclusions: These results suggest that $10 \mu \mathrm{M}$ ENC could protect hMSCs against toxic and oxidative effects of HQ. Therefore, ENC may have cancer protective effect.
\end{abstract}

(C) 2016. Multidisciplinary Cancer Investigation

\section{INTRODUCTION}

Cancer is related to a number of risk factors including oxidants. Nowadays, there is a tendency to find natural antioxidant compounds with minimal adverse effects to attenuate intracellular reactive oxygen species (ROS) accumulation [1]. Curcumin is a yellow polyphenolic pigment of the Curcuma longa plant which is largely insoluble in water [2]. Curcumin has been reported to exhibit a broad spectrum of pharma- cological effects, including antitumor, anti-inflammatory and antioxidant activities with low toxicity [36]. Among these properties, its potent anti-oxidative effect is renowned [7]. Despite these attractive attributes of curcumin, insolubility in aqueous solutions is one of the major drawbacks associated with the use of curcumin as a therapeutic agent [2]. Nano-encapsulation of curcumin could be a proper strategy to increase its aqueous solubility in therapeutic applications. Dendrosomes, a family of nontoxic nanoparti- 
cles, are suitable choices to increase the bioavailability of curcumin [8]. Previous studies in our laboratory revealed that dendrosome increases the curcumin uptake in the cells with no toxic effects [9].

Hydroquinone (HQ) is one of the serious benzene-derived primary metabolites produced by primary benzene hepatic oxidation [10]. Several studies have suggested that oxidative damages, which their effect on incidence of cancers have been reported, may be involved in the toxic effects of benzene [11, 12]. Benzene biological activation contains two stages: the first step occurs in the liver and yields the primary benzene metabolites, including phenol, catechol and hydroquinone [13]; in the next step, the primary metabolites transported to the bone marrow lead to the formation of ROS and induction of oxidative stress, which may play a crucial role in starting benzene toxicity $[14,15]$. Benzen by toxic effect on hMSCs may associate with development of leukemia.

Oxidative stress can arise from overproduction of ROS by metabolic reactions that use oxygen and shift the balance between oxidant/antioxidant status in favor of the oxidants [16]. In healthy organisms, ROS production is counterbalanced by the antioxidant defense system to maintain an appropriate redox balance [17]. In human, the anti-oxidative defense mechanism to escape the consequences of cell damage caused by ROS includes enzymes, such as catalase and superoxide dismutase, hemeoxygenase- 1 and low molecular compounds, e.g. glutathione $[18,19]$. However, the production of ROS in the body plays important roles in cellular signaling processes [20]. The generation of large amounts of ROS and free radicals without any affective neutralization system leads to oxidative damage in proteins, lipids and DNA [21], Oxidative stress is an important factor associated with many acute and chronic diseases including cancer, diabetes, cardiovascular, and neurodegenerative diseases [22].

Induction of ROS within the cells due to exposure to benzene and its metabolites has been well established [11]. Moreover, the major target tissue affected by benzene metabolite toxicity is bone marrow which contains hematopoietic and mesenchymal stem cells; so, the impressive toxicity of benzene metabolites affects this tissue $[23,24]$. Excessive exposure to benzene has been known to damage the bone marrow resulting in decreases in the numbers of circulating blood cells, and ultimately, aplastic anemia. Indeed, benzene metabolites induce mutagenesis which can eventually lead to the development of leukemia [25, 26].

The objective of the present study was to examine the protective potency of ENC against the oxidative effects of HQ on human mesenchymal stem cells (hM$\mathrm{SCs}$ ) as a main target of HQ toxicity.

\section{METHODS}

\section{Chemicals}

Curcumin was purchased from Merck KGaA (Darmstadt, Germany) with a purity of $95 \%$. Hydroquinone was the product of Sigma-Aldrich (St. Louis, USA). The dendrosome nanoparticle, specified Den O400, was a gift from the Institute of Biochemistry and Biophysics, University of Tehran, Iran.

Dullbecco's modified Eagle's medium (low-glucose DMEM), fetal bovine serum (FBS), phosphate-buffered saline (PBS) and trypsin-EDTA were purchased from Gibco BioCult (Paisley, Scotland, UK).

\section{Preparation of Drugs}

Dendrosome and curcumin powder were mixed in 25:1 ratio of dendrosome weight/curcumin weight based on optimized protocol and then diluted with PBS to have 10 $\mu \mathrm{M}$ ENC [8]. Aliquots of this solution were sterilized by $0.22 \mu \mathrm{m}$ filters and stored in a dark place at $4^{\circ} \mathrm{C}$. HQ powder was dissolved in low-glucose DMEM medium supplemented with $10 \%$ FBS $(10 \mathrm{mM})$ just before use and was kept away from light. The HQ solution was diluted to the desired $(15 \mu \mathrm{M}-150 \mu \mathrm{M})$ concentration for experiments.

\section{Cell Culture and Drug Treatment}

hMSCs (passage 1) were obtained from Royan Stem Cell Bank (RSCB), Iran and were cultured in low-glucose DMEM (Invitrogen/Life Technologies, Carlsbad, CA, USA) supplemented with $10 \% \mathrm{FBS}$ at $37^{\circ} \mathrm{C}$ in $95 \%$ air and $5 \% \mathrm{CO}_{2}$. Sterile stock solutions of chemicals were prepared in DMEM just before use. For treatment with these chemicals, cells (passage 3) were seeded in either multi-well plates or $25 \mathrm{~cm}^{2}$ cell culture flasks, and incubated until reaching 70\%-80\% confluence. The cells were then exposed to a range of chemical concentrations.

\section{Cell Viability Assay}

Cell viability was determined by the methylthiazol tetrazolium (MTT) reduction assay (Sigma-Aldrich, St. Louis, USA) according to the manufacturer's instruction. Briefly, hMSCs were seeded overnight in 96-well culture plates at a density of $1 \times 104$ cells/well. To test the cytoprotective effect of nanocurcumin against HQ-mediated cell death, the cells were pretreated with $10 \mu \mathrm{M}$ of nanocurcumin for 12 hours. The cells were then washed with PBS and stressed with different doses of HQ. After each treatment, media containing the treatment agents were removed and $5 \mathrm{mg} / \mathrm{mL}$ MTT in PBS was added to each well. After incubating at $37^{\circ} \mathrm{C}$ for four hours, the medium was removed and $200 \mu \mathrm{L}$ dimethyl sulfoxide solution (DMSO) was added to each well. The absorbance was measured at 570 $\mathrm{nm}$ in each well using a plate reader (Bio-RAD 680, USA). 
All the experiments were performed in triplicate and cell viability was calculated as the percentage of cell viability of treated cells against control cells.

\section{Estimation of Lipid Peroxidation}

To measure the extent of lipid peroxidation, a major marker of oxidative stress, the plasma content of malondialdehyde (MDA), an end product of membrane lipid peroxidation, was determined by the thiobarbituric acid-reactive substances (TBARS) assay in cell lysates. MDA forms a colored complex with thiobarbituric acid (TBA), which has the maximum absorbance at $532 \mathrm{~nm}$. The absorbance is proportional to the extent of membrane lipid peroxidation. Briefly, the cells were plated onto six-well plates and were treated with the considered drugs. After each treatment, the cells were lysed in the lysis buffer and then $100 \mu \mathrm{L}$ of the sample was added to $200 \mu \mathrm{L}$ ice-cold $10 \%$ TBA for 15 minutes to precipitate the protein. The experiments were performed on ice. The precipitated samples were centrifuged for 15 minutes at $1400 \mathrm{rpm} ; 200 \mu \mathrm{L}$ of each Supernatant was mixed with an equal volume of $0.67 \%$ thiobarbituric acid and then boiled for 30 minutes and the absorbance was read in $532 \mathrm{~nm}$. The remaining $50 \mu \mathrm{L}$ of supernatants were used for evaluating the protein content by Bradford assay. The lysis buffer used in these experiments contained EDTA $(1 \mathrm{mM})$, Tris- $\mathrm{HCl}(150$ $\mathrm{mM}$, Merck), $\mathrm{NaCl}(150 \mathrm{mM}$ ), Triton X100 (1\%, Sigma), DMSO (Gibco), and protease inhibitor PMSF (1 mM) in $\mathrm{pH}=7.4$.

\section{Estimation of Intracellular Reactive Oxygen Species}

The levels of intracellular ROS were monitored using the DCFH-DA fluorescent dye (Sigma Aldrich, USA). DCFH is initially a non-fluorescent dye and it is converted to a fluorescent molecule called 2,7-dichlorofluorescein (DCF) by oxidation. DCF was then quantified by fluorophotometry. After the treatment, the cells were collected and washed twice with PBS and then DCFHDA $(10 \mu \mathrm{M})$ was added into the medium for a further 30 minutes at $37^{\circ} \mathrm{C}$ and then it was analyzed by fluorescence spectrophotometer (PerkinElmer, Wellesley, MA, USA) with $485 \mathrm{~nm}$ excitation and $538 \mathrm{~nm}$ emission filters.

\section{Gene Expression}

\section{RNA Isolation, cDNA Synthesis and qRT-PCR}

Total RNA was isolated from passage $3 \mathrm{hMSCs}$ cultured in $25 \mathrm{~cm}^{2}$ flasks subsequent of each treatment. Total RNA was purified using $1 \mathrm{~mL}$ TRIzol reagent (Invitrogen). The quality and quantity of the extracted RNA were determined by $1 \%$ agarose gel and scientific NanoDrop 1000 spectrophotometer, respectively. Equal quantities of the total RNA from each sample were converted to cDNA using PrimeScript ${ }^{\text {tax }}$ RT reagent (Takara) in the presence of oligo (dT) and random hexanucleotide primers. Primers were designed by Allel ID software. Beta-2 microglobin $(\beta 2 \mathrm{M})$ was used as an internal control, which was stable during the experiment. All the primer sets had a calculated annealing temperature of $55^{\circ} \mathrm{C}$. The list of primer sequences for specific and house-keeping genes is indicated in Table 1.

Real-time PCR was performed in MicroAmp 96-well plates (Applied Biosystems) using SYBR Green supermix (Applied Biosystems, USA) in triplicates with a 20 $\mu \mathrm{L}$ final volume containing $10 \mu \mathrm{L}$ SYBR $^{\oplus}$ Premix Ex Taq ${ }^{r \mu}(2 \mathrm{X}), 0.4 \mu \mathrm{L}$ ROX, $1 \mu \mathrm{L}$ PCR primers, and finally $2 \mu \mathrm{L}$ diluted cDNA. The threshold cycle $(\mathrm{Ct})$ (the fractional cycle number at which the amount of amplified target reached a fixed threshold) was determined and Ct value of the target genes were normalized by the $\mathrm{Ct}$ value of the housekeeping gene $(\beta 2 \mathrm{M})$. Relative gene expression was calculated as $2^{-\Delta \Delta C t}$.

\section{Statistics}

Statistical analyses were performed using GraphPad InStat software. All the experiments were conducted in triplicate and the quantitative data are expressed as mean \pm SD (standard deviation) for each group. The Student's $t$-test and paired t-test were performed to assess the differences between the means. $P$ values less than 0.05 were considered statistically significant.

\section{RESULTS}

\section{MTT Assay}

hMSCs were exposed to different concentrations of ENC $(0-40 \mu \mathrm{M})$ and dendrosome $(0-40 \mu \mathrm{M})$ separately in three replicates for 24 hours. In order to assimilate the effect of dendrosome carriers in all the treatments, cells in zero concentration of ENC were only treated with dendrosome; $20 \mu \mathrm{M}$ concentration of ENC significantly reduced the hMSCs viability (Figure $1 \mathrm{~A}$ ). Data from the MTT assay showed that $10 \mu \mathrm{M}$ ENC was the effective non-toxic concentration for subsequent experiments. Treatment of the cells with dendrosome did not show any toxic effect on hMSCs.

Table 1: Nucleotide Sequences of the Primers Used for Real-time PCR

\begin{tabular}{lcccc}
\hline Gene & Accession number & Forward primer (5'-3') & Reverse primer(5'-3') & Amplicon size \\
\hline $\boldsymbol{\beta 2 M}$ & NM_004048.2 & AGATGTCTCGCTCCGTGG & TCTGCTGGATGACGTGAGTAA & 109 \\
$\mathbf{C A T}$ & NM_001752 & ACACTGCCAATGATGATAACG & GTTCTTGACCGCTTCTTCTG & 146 \\
HO1 & NM_002133.2 & ATGACACCAAGGACCAGAG & GTAAGGACCCATCGGAGAAG & 151 \\
\hline
\end{tabular}


Moreover, in order to study the protective effect of ENC against the toxic effect of $\mathrm{HQ}$, first the cells were pretreated with $10 \mu \mathrm{M}$ ENC for 12 hours; afterwards, the medium containing ENC was removed and the cells were exposed to different concentrations of hydroquinone $(0-150 \mu \mathrm{M})$ for an additional 24 hours. Results were compared with the cells exposed to the same HQ concentration without ENC pretreatment as control. As shown in Figure 1B, pretreatment of hMSCs with ENC protected the cells against the toxic effects of hydroquinone in $30 \mu \mathrm{M}$ and $60 \mu \mathrm{M}$ concentrations.
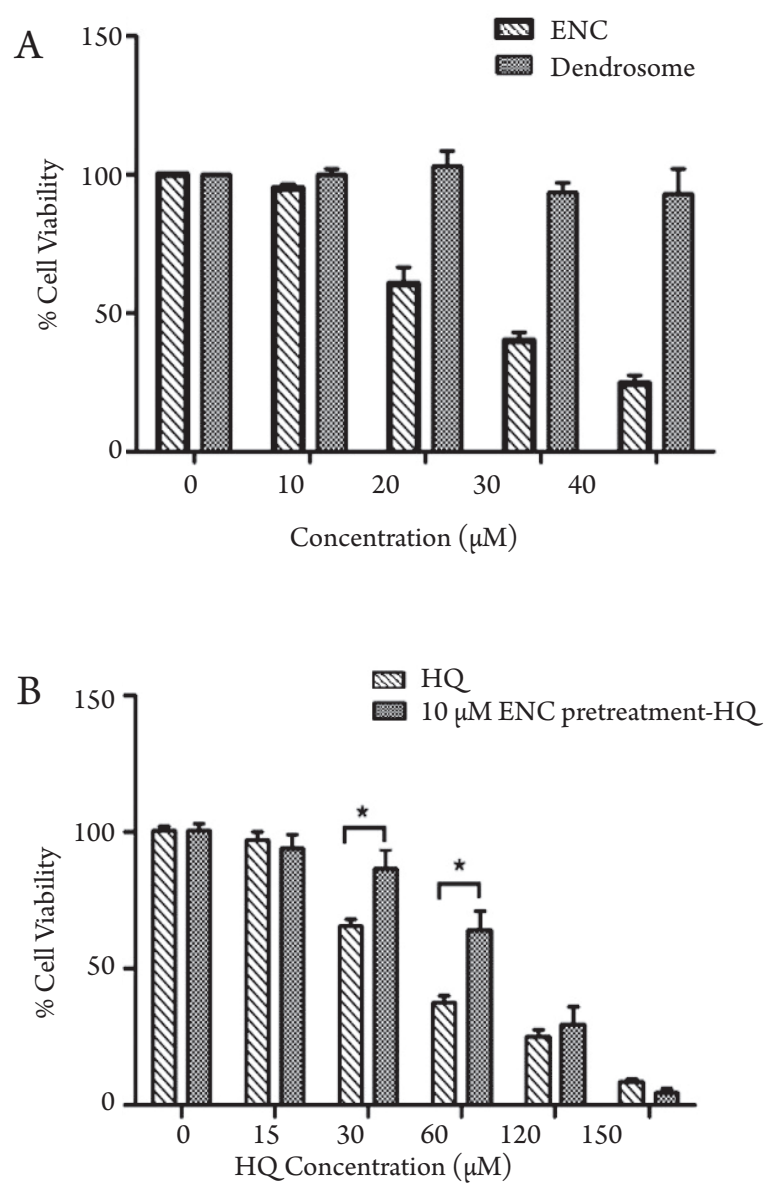

Figure 1: Evaluation of Cell Viability by MTT Assay.

(A) hMSCs were treated with different concentrations of ENC and dendrosome separately for 24 hours. (B) HQ: hMSCs were treated with different concentrations of hydroquinone for 24 hours, 10 $\mu \mathrm{M}$ ENC pretreatment- HQ: hMSCs were treated with $10 \mu \mathrm{M}$ ENC for 12 hours and after removing the ENC, the cells were exposed to different concentrations of hydroquinone for 24 hours. Data is presented as mean $\pm S D ; n=3,{ }^{*}: P<0.05$.

\section{Measurement of Lipid Peroxidation Extent}

Measurement of MDA versus protein content in the cells is one of the oxidative stress sensing indicators which shows the extent of lipid peroxidation [27]. For this purpose, hMSCs were pretreated with $10 \mu \mathrm{M}$ ENC and then were exposed to $30 \mu \mathrm{M}$ and $60 \mu \mathrm{M}$ of hydro- quinone. Lipid peroxidation in the cells was measured in terms of $\mathrm{nmol} / \mathrm{mg}$ protein. The results were compared with the cells exposed to the same HQ concentration without ENC pretreatment. At zero concentration of $\mathrm{HQ}$, cells were just treated with ENC. As shown in Figure 2, pretreatment of the cells with ENC reduced lipid peroxidation induced by HQ. The amount of protein in the cell lysate was measured by Bradford test [28] (Figure 3).

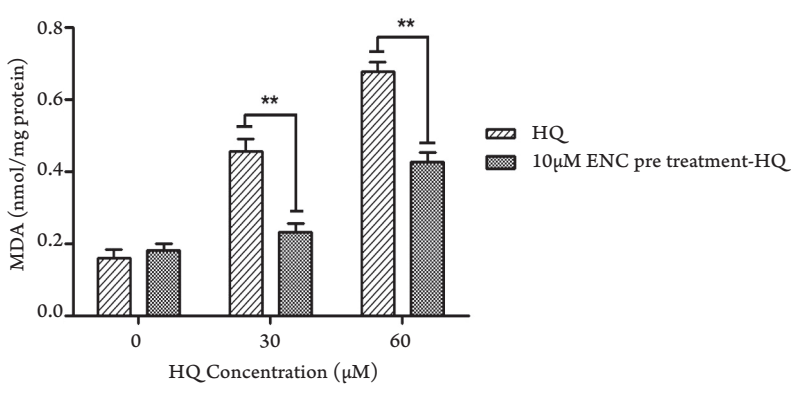

Figure 2: Malondialdehyde (MDA) Levels According to Protein Content in hMSCs After the Treatment.

HQ: hMSCs were exposed to hydroquinone for 24 hours, $10 \mu \mathrm{M}$ ENC pretreatment-HQ: hMSCs were treated with $10 \mu \mathrm{M} \mathrm{ENC} \mathrm{for}$ 12 hours and after removing the medium containing ENC, the cells were exposed to $\mathrm{HQ}(30$ and $60 \mu \mathrm{M})$ for 24 hours. Data is presented as mean $\pm \mathrm{SD}, \mathrm{n}=3$; $^{* *}$ : $\mathrm{P}<0.01$.

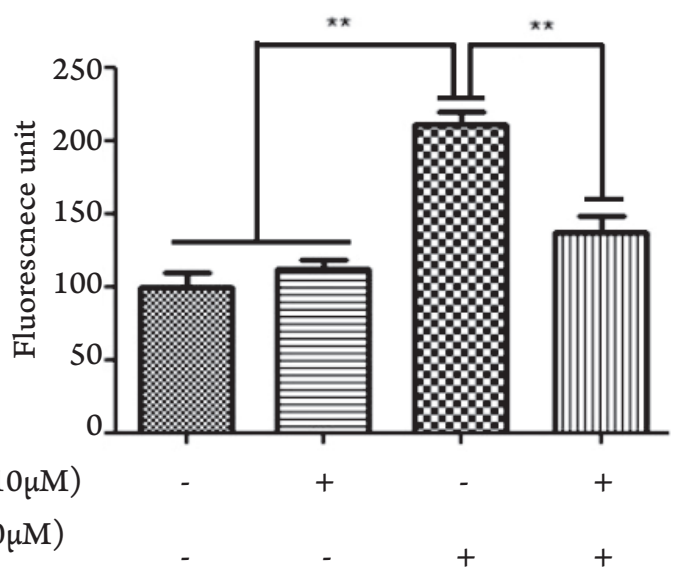

Figure 3: Evaluation of ROS Production After Each Treatment Using DCFH-DA Assay.

In treatment with both ENC and $\mathrm{HQ}$ hMSCs were exposed to 10 $\mu \mathrm{M}$ ENC for 12 hours and after removing the medium, the cells were treated with $60 \mu \mathrm{M}$ HQ for 24 hours. Data are presented as mean $\pm S D ; n=3 .{ }^{* *}: \mathrm{P}<0.01$.

\section{Measurement of Intracellular ROS}

Measurement of intracellular ROS using DCFH-DA probe showed that treatment of the cells with $60 \mu \mathrm{M}$ HQ significantly increased DCF fluorescent intensity, but treatment with $10 \mu \mathrm{M}$ ENC did not show any significant increase in the amount of intracellular ROS compared with the control group (cells with probe 
only). Pretreatment of the cells with $10 \mu \mathrm{M}$ ENC and then treatment with $60 \mu \mathrm{M}$ HQ caused a significant decrease in the levels of intracellular ROS. Results were compared to the cells exposed to the same HQ concentration without ENC pretreatment.

\section{Changes in Gene Expression}

Alterations in expression levels of antioxidant genes (CAT and HO1) were measured by real-time PCR technique. As presented in Figure 4, ENC treatment of hMSCs increased the catalase gene expression significantly 24 and 36 hours after the treatment compared to the control. This up-regulation in $\mathrm{HO} 1$ gene expression occurred 12 hours after the treatment. Moreover, pretreatment of hMSCs with ENC and then exposure to HQ significantly elevated the mRNA level of $H O 1$ and CAT genes compared to HQ treatment alone. Therefore, this elevated expression can be attributed to the presence of ENC in the medium (Figure 5).

\section{DISCUSSION}

Occupational or environmental exposures to benzene may cause several adverse health effects. Hydroquinone, a major benzene metabolite, is recognized to induce oxidative stress in the cells and tissues. Bone marrow, the niche of mesenchymal stem cells, is the main target tissue affected by benzene toxicity $[14,15]$. ROS can promote many aspects of tumor development and progression. Indeed, cancer initiation has been related to oxidative stress by increasing DNA mutations, protein and polysaccharide damages and epigenetic changes $[29,30]$.

In recent years, there has been a trend toward the consumption of natural antioxidants, preventing the formation of radicals, scavenging them, or promoting their decomposition [31]. The supplementation of food with traditional antioxidants has been shown to be protective against cancer in a large number of studies [32-34]. The phytochemichal curcumin, a major component of turmeric, has been known as a potent antioxidant used in herbal medicine [7]. Curcumin has been shown to exhibit several activities including antioxidant, anti-inflammatory and anti-carcinogenic $[9,35,36]$. A growing body of evidence has substantiated the neuroprotective, hepatoprotective and cardioprotective effects of curcumin in rat and mice [37-39]. Recently, dendrosomal ENC has been widely used to increase the bioavailability of this compound [8,40].

Here, we evaluated the protective effect of ENC on hMSCs exposed to HQ. In order to evaluate the toxic effect of ENC and HQ on hMSCs, cells were exposed to different concentration of chemicals and the percentage of cell viability was assessed by MTT assay. The results showed that HQ considerably decreased the cell viability, but pretreatment of the cells with ENC and subse- quent treatment with HQ caused improvement in cell

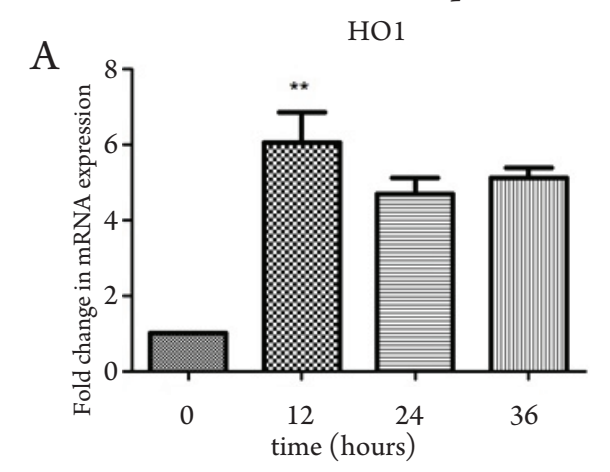

B

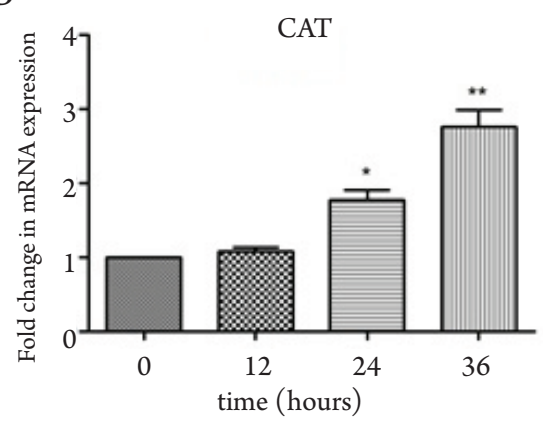

Figure 4: The Effect of $10 \mu \mathrm{M}$ ENC on the Expression Level of Antioxidant Genes (CAT and HO1) in hMSCs at 12, 24 and 36 Hours After the Treatment.

Data are presented as mean $\pm S D ; n=3,{ }^{*}: \mathrm{P}<0.05,{ }^{* *}: \mathrm{P}<0.01$.

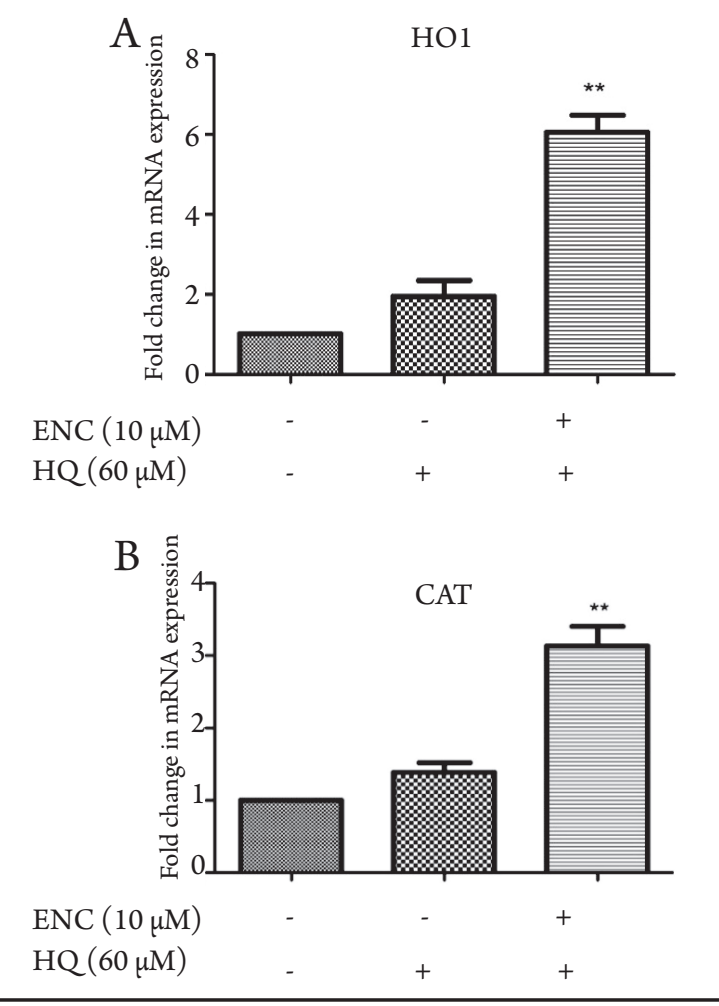

Figure 5: Alterations in the Antioxidant Genes Expressions Occurred Due to Different Treatments.

In treatment with both ENC and HQ, hMSCs were exposed to 10 $\mu \mathrm{M}$ ENC for 12 hours and after removing the medium, the cells were treated with $60 \mu \mathrm{M}$ HQ for 24 hours. Data are presented as mean $\pm \mathrm{SD},{ }^{* *}: \mathrm{P}<0.01$. 
viability. However, at higher concentrations of hydroquinone (> $120 \mu \mathrm{M})$, ENC was not able to inhibit cell death anymore. Similar results in mouse neuroblastoma cells showed that pretreatment of cells with $25 \mu \mathrm{g} /$ $\mathrm{mL}$ curcumin reduced the cell death induced by $\mathrm{H}_{2} \mathrm{O}_{2}$ treatment dramatically [41]. Moreover, we assessed the protective effect of ENC on HQ pretreated cells. The results showed no significant differences between the two groups of HQ treated cells and ENC treatment on HQ pretreated cells (Data not shown).

Next, we sought to investigate the effect of ENC and HQ on levels of intracellular ROS. The results showed that treatment of hMSCs with HQ caused an increase in intracellular ROS compared to the non-treated cells. It seems that HQ could play a crucial role in the induction of oxidative stress in hMSCs. However, pretreatment of the cells with ENC and subsequent exposure to HQ reduced intracellular ROS, but ROS levels did not return to the levels of control cells. Therefore, it can be deduced that $10 \mu \mathrm{M}$ ENC may scavenge free radicals induced by HQ in hMSCs. Previously, other studies showed that curcumin was able to scavenge the additional ROS induced by $\mathrm{H}_{2} \mathrm{O}_{2}$ or UVB radiation in human lens epithelial cells $[7,42]$. ROS are highly reactive molecules and can induce lipid peroxidation and disrupt membrane lipid bilayer functions [43]. Lipid peroxidation products such as TBARS have been used as indirect biomarkers of oxidative stress [27]. Accordingly, the extent of lipid peroxidation was assessed by TBARS assay. Treatment of hMSCs with HQ showed a significant increase in the levels of lipid peroxidation, while pretreatment of the cells with ENC and then exposure to the same concentrations of HQ reduced the lipid peroxidation rates in the cells. Although, this extent did not decrease to the initial value (without treatment with HQ). These results suggest that ENC can provide a substantial protection against the oxidative damage induced by HQ on hMSCs.

According to the results mentioned above, we concluded that ENC may act as an antioxidant by enhancing the antioxidant enzyme gene expression. Analyzing the alteration in the expression of antioxidant genes, CAT and $H O 1$, in different treatments showed that $C A T$ and $\mathrm{HO} 1$ were up-regulated after ENC treatment. Moreover, ENC pretreatment of the cells and subsequent exposure to HQ caused considerable up-regulation in CAT and HO1 gene expression compared to the cells which were solely treated with HQ. Because of the fact that $\mathrm{H}_{2} \mathrm{O}_{2}$ is one of the major species of ROS induced by benzene metabolites and since catalase has a main role in $\mathrm{H}_{2} \mathrm{O}_{2}$ decomposition [11], it seems that catalase is one of the effective enzymes involved in the protective effect of ENC against the oxidative damage of HQ in hMSCs. There are some evidences that up-regulation of $\mathrm{HO} 1$ by curcumin is mediated by elevated expression of NF-E2-related factor 2 (Nrf2) [44, 45]. Nrf2 transcription factor plays a key role in the induction of genes containing ARE sequences in their promoter and curcumin is also known as a potent activator of $\mathrm{Nrf2}$ [45].

Therefore, curcumin could exert antioxidative effects either directly as a chemical antioxidant due to its ability to scavenge reactive oxygen or by modulating cellular defenses, which themselves exert antioxidant effects such as up-regulation of antioxidative enzymes. Taken together, these data provides evidence that ENC is able to protect hMSCs against oxidative damaging effects induced by HQ. Therefore, ENC may have cancer protective effect.

However, previous studies showed that curcumin exhibited both antioxidant and pro-oxidant activity in a concentration dependent manner [46].

\section{ACKNOWLEDGMENTS}

This work was financially supported by the Department of Genetics, Faculty of Biological Sciences, Tarbiat Modares University.

\section{CONFLICT OF INTEREST}

The authors declared that there was no conflict of interests.

\section{REFERENCES}

1. Eybl V, Kotyzova D, Koutensky J. Comparative study of natural antioxidants - curcumin, resveratrol and melatonin - in cadmium-induced oxidative damage in mice. Toxicology. 2006;225(23):150-6. DOI: 10.1016/j.tox.2006.05.011 PMID: 16806632

2. Anand P, Kunnumakkara AB, Newman RA, Aggarwal BB. Bioavailability of curcumin: problems and promises. Mol Pharm. 2007;4(6):807-18. DOI: $10.1021 / \mathrm{mp} 700113 \mathrm{r}$ PMID: 17999464

3. Araujo CC, Leon LL. Biological activities of Curcuma longa L. Mem Inst Oswaldo Cruz. 2001;96(5):723-8. DOI: S007402762001000500026 PMID: 11500779

4. Venkatesan P, Rao MN. Structure-activity relationships for the inhibition of lipid peroxidation and the scavenging of free radicals by synthetic symmetrical curcumin analogues. J Pharm Pharmacol. 2000;52(9):1123-8. DOI: 10.1211/0022357001774886 PMID: 11045893

5. Joe B, Vijaykumar M, Lokesh BR. Biological properties of curcumin-cellular and molecular mechanisms of action. Crit Rev Food Sci Nutr. 2004;44(2):97-111. DOI: 10.1080/10408690490424702 PMID: 15116757

6. Shang YJ, Jin X, Shang XL, Tang JJ, Liu GY, Dai F, et al. Antioxidant capacity of curcumin-directed analogues: Structure-activity relationship and influence of microenvironment. Food Chemistry. 2010;119(4):1435-42. DOI: 10.1016/j.foodchem.2009.09.024

7. Ak T, Gulcin I. Antioxidant and radical scavenging properties of curcumin. Chem Biol Interact. 2008;174(1):27-37. DOI: 10.1016/j.cbi.2008.05.003 PMID: 18547552

8. Babaei E, Sadeghizadeh M, Hassan ZM, Feizi MA, Najafi F, Hashemi SM. Dendrosomal curcumin significantly suppresses cancer cell proliferation in vitro and in vivo. Int Immunopharmacol. 2012;12(1):226-34. DOI: 10.1016/j.intimp.2011.11.015 PMID: 22155627

9. Tahmasebi Birgani M, Erfani-Moghadam V, Babaei E, Najafi F, Zamani M, Shariati M, et al. Dendrosomal nano-curcumin; The 
novel formulation to improve the anticancer properties of curcumin. Progres Biol Sci. 2015;5(2):143-58.

10. Ross D. Metabolic basis of benzene toxicity. Eur J Haematol Suppl. 1996;60:111-8. DOI: 10.1111/j.1600-0609.1996. tb01656.x PMID: 8987252

11. Shen Y, Shen HM, Shi CY, Ong CN. Benzene metabolites enhance reactive oxygen species generation in HL60 human leukemia cells. Hum Exp Toxicol. 1996;15(5):422-7. DOI: 10.1177/096032719601500510 PMID: 8735467

12. Snyder R, Hedli CC. An overview of benzene metabolism. Environ Health Perspect. 1996;104 Suppl 6:1165-71. DOI: 10.1289/ehp.961041165 PMID: 9118888

13. Parke DV, Williams RT. Studies in detoxication. 54. The metabolism of benzene. (a) The formation of phenylglucuronide and phenylsulphuric acid from [14C]benzene. (b) The metabolism of [14C]phenol. Biochem J. 1953;55(2):337-40. DOI: 10.1042/bj0550337 PMID: 13093687

14. Barreto G, Madureira D, Capani F, Aon-Bertolino L, Saraceno E, Alvarez-Giraldez LD. The role of catechols and free radicals in benzene toxicity: an oxidative DNA damage pathway. Environ Mol Mutagen. 2009;50(9):771-80. DOI: 10.1002/ em.20500 PMID: 19449395

15. Subrahmanyam VV, Ross D, Eastmond DA, Smith MT. Potential role of free radicals in benzene-induced myelotoxicity and leukemia. Free Radic Biol Med. 1991;11(5):495-515. DOI: 10.1016/0891-5849(91)90063-9 PMID: 1769608

16. Poljsak B, Suput D, Milisav I. Achieving the balance between ROS and antioxidants: when to use the synthetic antioxidants. Oxid Med Cell Longev. 2013;2013:956792. DOI: 10.1155/2013/956792 PMID: 23738047

17. Rahal A, Kumar A, Singh V, Yadav B, Tiwari R, Chakraborty $S$, et al. Oxidative stress, prooxidants, and antioxidants: the interplay. Biomed Res Int. 2014;2014:761264. DOI: 10.1155/2014/761264 PMID: 24587990

18. Kinnula VL, Soini Y, Kvist-Makela K, Savolainen ER, Koistinen P. Antioxidant defense mechanisms in human neutrophils. Antioxid Redox Signal. 2002;4(1):27-34. DOI: 10.1089/152308602753625825 PMID: 11970840

19. Maxwell SR. Prospects for the use of antioxidant therapies. Drugs. 1995;49(3):345-61. DOI: 10.2165/00003495199549030-00003 PMID: 7774511

20. Hoidal JR. Reactive oxygen species and cell signaling. Am J Respir Cell Mol Biol. 2001;25(6):661-3. DOI: 10.1165/ ajrcmb.25.6.f213 PMID: 11726388

21. Sharma P, Jha AB, Dubey RS, Pessarakli M. Reactive oxygen species, oxidative damage, and antioxidative defense mechanism in plants under stressful conditions. J Botany. 2012;7(2):190-9. DOI: $10.1155 / 2012 / 217037$

22. Khansari N, Shakiba Y, Mahmoudi M. Chronic inflammation and oxidative stress as a major cause of age-related diseases and cancer. Recent Pat Inflamm Allergy Drug Discov. 2009;3(1):7380. DOI: $10.2174 / 187221309787158371$ PMID: 19149749

23. Atkinson TJ. A review of the role of benzene metabolites and mechanisms in malignant transformation: summative evidence for a lack of research in nonmyelogenous cancer types. Int J Hyg Environ Health. 2009;212(1):1-10. DOI: 10.1016/j. ijheh.2007.09.013 PMID: 18178523

24. Zhou H, Kepa JK, Siegel D, Miura S, Hiraki Y, Ross D. Benzene metabolite hydroquinone up-regulates chondromodulin-I and inhibits tube formation in human bone marrow endothelial cells. Mol Pharmacol. 2009;76(3):579-87. DOI: 10.1124/ mol.109.057323 PMID: 19525446

25. Snyder R. Leukemia and benzene. Int J Environ Res Public Health. 2012;9(8):2875-93. DOI: 10.3390/ijerph9082875 PMID: 23066403

26. Meek ME, Klaunig JE. Proposed mode of action of benzene-induced leukemia: Interpreting available data and identifying critical data gaps for risk assessment. Chem Biol Interact.
2010;184(1-2):279-85. DOI: 10.1016/j.cbi.2010.02.006 PMID: 20153303

27. Ho E, Karimi Galougahi K, Liu CC, Bhindi R, Figtree GA. Biological markers of oxidative stress: Applications to cardiovascular research and practice. Redox Biol. 2013;1(1):483-91. DOI: 10.1016/i.redox.2013.07.006 PMID: 24251116

28. Bradford MM. A rapid and sensitive method for the quantitation of microgram quantities of protein utilizing the principle of protein-dye binding. Anal Biochem. 1976;72(1-2):248-54. DOI: 10.1016/0003-2697(76)90527-3 PMID: 942051

29. Ozben T. Oxidative stress and apoptosis: impact on cancer therapy. J Pharm Sci. 2007;96(9):2181-96. DOI: 10.1002/ jps.20874 PMID: 17593552

30. Gupta SC, Hevia D, Patchva S, Park B, Koh W, Aggarwal BB. Upsides and downsides of reactive oxygen species for cancer: the roles of reactive oxygen species in tumorigenesis, prevention, and therapy. Antioxid Redox Signal. 2012;16(11):1295322. DOI: $10.1089 /$ ars.2011.4414 PMID: 22117137

31. Lobo V, Patil A, Phatak A, Chandra N. Free radicals, antioxidants and functional foods: Impact on human health. Pharmacogn Rev. 2010;4(8):118-26. DOI: 10.4103/0973-7847.70902 PMID: 22228951

32. Kirsh VA, Peters U, Mayne ST, Subar AF, Chatterjee N, Johnson $\mathrm{CC}$, et al. Prospective study of fruit and vegetable intake and risk of prostate cancer. J Natl Cancer Inst. 2007;99(15):1200-9. DOI: 10.1093/jnci/djm065 PMID: 17652276

33. Zhang CX, Ho SC, Chen YM, Fu JH, Cheng SZ, Lin FY. Greater vegetable and fruit intake is associated with a lower risk of breast cancer among Chinese women. Int J Cancer. 2009;125(1):1818. DOI: $10.1002 /$ ijc.24358 PMID: 19358284

34. Agudo A, Cabrera L, Amiano P, Ardanaz E, Barricarte A, Berenguer $\mathrm{T}$, et al. Fruit and vegetable intakes, dietary antioxidant nutrients, and total mortality in Spanish adults: findings from the Spanish cohort of the European Prospective Investigation into Cancer and Nutrition (EPIC-Spain). Am J Clin Nutr. 2007;85(6):1634-42. PMID: 17556703

35. Al-Jassabi S, Ahmed KA, Abdulla MA. Antioxidant effect of curcumin against microcystin-LR-induced renal oxidative damage in Balb/c mice. Trop J Pharm Res. 2012;11(4):531-6. DOI: 10.4314/tjpr.v11i4.2

36. Bereswill S, Munoz M, Fischer A, Plickert R, Haag LM, Otto $B$, et al. Anti-inflammatory effects of resveratrol, curcumin and simvastatin in acute small intestinal inflammation. PLoS One. 2010;5(12):e15099. DOI: 10.1371/journal.pone.0015099 PMID: 21151942

37. Swamy AV, Gulliaya S, Thippeswamy A, Koti BC, Manjula DV. Cardioprotective effect of curcumin against doxorubicin-induced myocardial toxicity in albino rats. Indian J Pharmacol. 2012;44(1):73-7. DOI: 10.4103/0253-7613.91871 PMID: 22345874

38. Wang R, Li YH, Xu Y, Li YB, Wu HL, Guo H, et al. Curcumin produces neuroprotective effects via activating brain-derived neurotrophic factor/TrkB-dependent MAPK and PI-3K cascades in rodent cortical neurons. Prog Neuropsychopharmacol Biol Psychiatry. 2010;34(1):147-53. DOI: 10.1016/j. pnpbp.2009.10.016 PMID: 19879308

39. Tarasub N, Narula K, Ayutthaya WDN. Effects of curcumin on cadmium-induced hepatotoxicity in rats. Thai $\mathrm{J}$ Toxicol. 2010;23(2):100-07.

40. Tahmasebi Mirgani M, Isacchi B, Sadeghizadeh M, Marra F, Bilia AR, Mowla SJ, et al. Dendrosomal curcumin nanoformulation downregulates pluripotency genes via miR-145 activation in U87MG glioblastoma cells. Int J Nanomedicine. 2014;9:40317. DOI: $10.2147 / \mathrm{IJN} . S 48136$ PMID: 24531649

41. Zhao XC, Zhang L, Yu HX, Sun Z, Lin XF, Tan C, et al. Curcumin protects mouse neuroblastoma Neuro-2A cells against hydrogen-peroxide-induced oxidative stress. Food Chem. 2011;129(2):387-94. DOI: 10.1016/j.foodchem.2011.04.089 
42. Chhunchha B, Fatma N, Bhargavan B, Kubo E, Kumar A, Singh DP. Specificity protein, Spl-mediated increased expression of Prdx6 as a curcumin-induced antioxidant defense in lens epithelial cells against oxidative stress. Cell Death Dis. 2011;2(11):e234. DOI: 10.1038/cddis.2011.121 PMID: 22113199

43. Girotti AW. Mechanisms of lipid peroxidation. J Free Radic Biol Med. 1985;1(2):87-95. DOI: 10.1016/0748-5514(85)90011 X PMID: 3915303

44. Motterlini R, Foresti R, Bassi R, Green CJ. Curcumin, an antioxidant and anti-inflammatory agent, induces heme oxygenase- 1 and protects endothelial cells against oxidative stress. Free
Radic Biol Med. 2000;28(8):1303-12. DOI: 10.1016/S08915849(00)00294-X PMID: 10889462

45. Balogun E, Hoque M, Gong P, Killeen E, Green CJ, Foresti R et al. Curcumin activates the haem oxygenase- 1 gene via regulation of Nrf2 and the antioxidant-responsive element. Biochem J. 2003;371(Pt 3):887-95. DOI: 10.1042/BJ20021619 PMID: $\underline{12570874}$

46. Banerjee A, Kunwar A, Mishra B, Priyadarsini KI. Concentration dependent antioxidant/pro-oxidant activity of curcumin studies from AAPH induced hemolysis of RBCs. Chem Biol Interact. 2008;174(2):134-9. DOI: 10.1016/j.cbi.2008.05.009 PMID: 18571152 